\title{
HUBUNGAN ANTARA PENGETAHUAN DAN SIKAP DENGAN TINDAKAN PETUGAS KESEHATAN DALAM UPAYA PENGELOLAAN SAMPAH MEDIS DI PUSKESMAS DAWAN II TAHUN 2021
}

\section{Kadek Ari Widyasari'1, I Nyoman Sujaya²}

\begin{abstract}
The Public Health is a functional organization unit that organizes health efforts that are comprehensive and integrated, evenly accepted and affordable by the community. The purpose of this study was to determine the relationship between knowledge and attitudes of health workers and actions in efforts to manage medical waste at Dawan II Public Health Center in 2021. This research is a type of quantitative research with a cross sectional approach with a population of all health workers totaling 63 people with the instruments used in the form of questionnaires and observation sheets. The analysis was carried out by univariate and bivariate with the Chi-square test. Based on hypothesis testing, it is known that the knowledge of health workers in efforts to manage medical waste at the health center has a P-Value $=0.001$ <significance $p=0.05$. Meanwhile, the attitude of health workers in the efforts to manage medical waste at the health centers has a P-Value $=0.001$ $<$ significance $p=0.05$. So it can be concluded that there is a relationship between knowledge and attitudes with the actions of health workers in efforts to manage medical waste at Dawan II Public Health Center in 2021.
\end{abstract}

Keywords: Knowledge, Attitude, Medical Waste Management

\section{PENDAHULUAN}

Puskesmas merupakan kesatuan organisasi fungsional yang menyelenggarakan upaya kesehatan yang bersifat menyeluruh terpadu merata dapat diterima dan terjangkau oleh masyarakat dengan peran serta aktif masyarakat dan menggunakan hasil pengembangan ilmu pengetahuan dan teknologi tepat guna ${ }^{1}$. Puskesmas 
dalam kegiatannya menghasilkan limbah medis maupun limbah non medis baik dalam bentuk padat maupun cair. Limbah medis dalam bentuk padat dihasilkan dari kegiatan yang berasal dari ruang perawatan seperti poliklinik gigi, poliklinik umum poliklinik gigi, poliklinik Ibu dan anak, laboratorium dan apotek. Sementara itu, limbah cair berasal dari laboratorium puskesmas yang mungkin mengandung mikroorganisme, bahan kimia beracun, dan radioaktif ${ }^{2}$. Sekitar 70-90\% limbah padat yang berasal dari instalasi kesehatan merupakan limbah umum yang menyerupai limbah rumah tangga dan tidak mengandung resiko. Sisanya sekitar 10-25\% merupakan limbah yang dapat menimbulkan berbagai jenis dampak kesehatan karena dipandang berbahaya ${ }^{3}$

Metode pengelolaan sampah medis padat melalui beberapa tahap mulai dari pemilahan, pengumpulan, penampungan pengangkutan, pemusnahan titik. Pengelolaan limbah medis yang tidak baik dapat menimbulkan masalah terhadap kesehatan dan lingkungan. Pemisahan sampah medis sejak dari ruangan yang dilakukan oleh petugas kesehatan merupakan langkah awal untuk memperkecil kontaminasi medis dan non medis di puskesmas maupun pada masyarakat ${ }^{4}$.

Puskesmas Dawan II merupakan salah satu puskesmas yang terletak di Kabupaten Klungkung, berdasarkan data yang diperoleh dari Puskesmas Dawan II, jumlah timbulan sampah medis rata-rata sebanyak 1-2 kg/hari dengan hitungan jumlah setiap bulannya antara 50-60 kg. Puskesmas Dawan II melakukan pengelolaan sampah dengan pemilahan, pewadahan, dan penyimpanan dengan sistem pengelolaan sampah medis yang dilakukan dari sumber yaitu setiap ruangan pelayanan medis, pemilahan dilakukan oleh setiap petugas kesehatan yang bertugas dengan membuang sampah pada tempat yang sudah disediakan.

Berdasarkan pengamatan awal peneliti, diketahui jika Puskesmas Dawan II sudah memiliki Standar Operasional Prosedur (SOP) pengelolaan sampah medis dan non medis, tetapi letak lembaran SOP 
berada pada ruangan penyimpanan sampah medis yang tidak semua petugas kesehatan dapat melihatnya, terkadang petugas kesehatan memilih menghubungi tenaga sanitarian jika merasa kurang tepat dalam pengelolaan sampah medis dari sumber (ruang perawatan). Permasalahan lain yaitu pengangkutan sampah medis sering terlambat dikarenakan pihak ketiga yang diajak bekerjasama sering melewatkan waktu pengangkutan sehingga memicu risiko perkembangan mikroorganisme patogen. Selain itu, dikarenakan adanya pandemi Covid-19, adapun jenis sampah medis kategori lainnya yang dikelola oleh pihak Puskesmas Dawan II yaitu sampah medis hasil penanganan pasien atau kegiatan yang berhubungan dengan Covid-19. Dengan keadaan seperti itu, puskesmas tersebut tetap membutuhkan pengelolaan profesional untuk mengatasi agar tidak terjadi kontaminasi terhadap lingkungan internal maupun eksternal.

Tujuan dari penelitian ini adalah untuk mengetahui hubungan antara pengetahuan dan sikap dengan tindakan petugas kesehatan dalam upaya pengelolaan sampah medis di Puskesmas Dawan II Tahun 2021.

\section{METODE PENELITIAN}

Penelitian ini merupakan jenis penelitian kuantitatif dengan pendekatan cross sectional yang bertujuan untuk mempelajari dinamika korelasi antara faktor-faktor risiko dengan efek, dengan cara pendekatan, observasi atau pengumpulan data sekaligus pada suatu waktu ${ }^{5}$. Dalam penelitian ini, variabel bebas yang diteliti adalah pengetahuan dan sikap petugas kesehatan puskesmas, variabel terikat dalam penelitian ini adalah tindakan petugas kesehatan dalam upaya pengelolaan sampah medis, dan variabel penganggu dalam penelitian ini adalah pemberian edukasi pada petugas medis dan fasilitas yang disediakan oleh puskesmas dalam upaya pengelolaan sampah medis. Penelitian ini dilaksanakan di

Puskesmas Dawan II Kecamatan Dawan Kabupaten Klungkung dimulai pada bulan Februari sampai dengan April 2021. Populasi dalam penelitian ini adalah tenaga kesehatan yang 
bekerja di Puskesmas Dawan II Kecamatan Dawan Kabupaten Klungkung dengan sampel berjumlah sebanyak 63 orang.

Teknik pengambilan sampel dalam penelitian ini adalah total sampling titik total sampling adalah teknik pengambilan sampel dimana jumlah sampel sama ${ }^{6}$. Pengumpulan data primer dilakukan dengan wawancara langsung kepada responden dengan bantuan lembar observasi dan kuisioner tentang pengetahuan, sikap, dan tindakan petugas kesehatan terhadap pengelolaan sampah di puskesmas. Sedangkan pengumpulan data sekunder diperoleh dari data kepegawaian Puskesmas Dawan II Kecamatan Dawan Kabupaten Klungkung. Pada proses analisis data, analisis yang digunakan adalah analisis univariate yang bertujuan untuk menjelaskan atau mendeskripsikan karakteristik setiap variabel penelitian titik bentuk analisis univariat tergantung dari jenis datanya, dan analisis bivariate yang dilakukan terhadap dua variabel yang diduga berhubungan atau berkorelasi 7 . Analisis univariat akan mempergunakan uji statistic Chi Square.

\section{HASIL DAN PEMBAHASAN}

\section{Karakteristik responden}

Dari total 63 responden yang dijadikan sampel penelitian, kelompok umur paling banyak antara 31-40 tahun sebanyak 28 orang $(44,4 \%)$, dengan jenis kelamin yang paling dominan yaitu perempuan dengan jumlah 44 orang $(69,8 \%)$. Seluruh responden yang diambil datanya merupakan petugas kesehatan yang memiliki latar belakang lulusan Diploma/Perguruan Tinggi, dan sebagian besar responden memiliki masa bekerja selama >10 tahun sebanyak 30 orang $(47,6 \%)$.

\section{Distribusi variabel penelitian}

a. Pengetahuan responden

Berdasarkan hasil penelitian dari 63 sampel, mayoritas responden memiliki pengetahuan tentang upaya pengelolaan sampah medis puskesmas dengan nilai baik sebanyak 54 responden (85,7\%). Hal ini menunjukan bahwa petugas kesehatan Puskesmas Dawan II memiliki pengetahuan yang cukup baik dan 
sudah memahami cara yang tepat untuk mengelola sampah medis yang dihasilkan dari kegiatan pelayanan puskesmas ditempatnya berkerja.

b. Sikap responden

Berdasarkan hasil yang telah didapatkan, jumlah responden yang memiliki sikap positif dalam upaya pengelolaan sampah medis sebanyak 58 orang responden $(92,1 \%)$, nilai ini jauh lebih besar daripada kategori negatif. Dengan hasil yang didapatkan tersebut dapat dikatakan bahwa petugas kesehatan dominan memiliki sikap dominan positif. c. Tindakan responden

Berdasarkan hasil data yang didapatkan, jumlah petugas kesehatan yang memiliki tindakan kategori baik dalam upaya pengelolaan sampah medis sebanyak 54 responden $(85,7 \%)$. Hasil yang didapatkan dapat menunjukan bahwa tindakan pengelolaan sampah medis yang dilakukan petugas kesehatan puskesmas dominan baik, namun dilihat dari tindakan, terdapat beberapa petugas kesehatan puskesmas masih kurang memperhatikan tindakan pengelolaan sampah medis.

\section{Analisis hubungan antar variabel}

a. Hubungan pengetahuan dengan tindakan dalam upaya pengelolaan sampah medis Tabel 1

Tabulasi Silang Pengetahuan Terhadap Tindakan Petugas Kesehatan Dalam Upaya Pengelolan Sampah Medis Di Puskemas Dawan II Tahun 2021

\begin{tabular}{|c|c|c|c|c|c|c|c|}
\hline \multirow{3}{*}{ Pengetahuan } & \multicolumn{4}{|c|}{ Tindakan } & \multirow{2}{*}{\multicolumn{2}{|c|}{ Total }} & \multirow{3}{*}{$\begin{array}{c}P- \\
\text { Value }\end{array}$} \\
\hline & \multicolumn{2}{|c|}{ Tidak Baik } & \multicolumn{2}{|c|}{ Baik } & & & \\
\hline & $\mathbf{N}$ & $\%$ & $\mathbf{N}$ & $\%$ & $\mathbf{n}$ & $\%$ & \\
\hline Tidak Baik & 7 & 11,1 & 2 & 3,2 & 9 & 14,3 & 0,000 \\
\hline Baik & 2 & 3,2 & 52 & 82,5 & 54 & 85,7 & \\
\hline \multirow[t]{2}{*}{ Total } & 9 & 14,3 & 54 & 85,7 & 63 & 100 & \\
\hline & \multicolumn{6}{|c|}{$\mathrm{OR}=91,0 ; \mathrm{CI} 95 \%=11,001-752,728$} & \\
\hline
\end{tabular}

Hasil uji statistik didapatkan $P$ Value $=0,000$ dimana hasil yang diperoleh lebih kecil dari nilai alfa $p$ atau sig sebesar 0,05, dapat disimpulkan bahwa terdapat hubungan antara pengetahuan dengan tindakan petugas kesehatan dalam upaya pengelolaan sampah medis. Nilai OR 
pada tabel adalah sebesar 91,0 dan nilai CI pada tabel adalah berkisar antara $11,001-752,728$.

Meskipun nilai dominan yang diperoleh adalah kategori baik, namun masih terdapat beberapa hasil kurang baik yang disebabkan oleh kurangnya pengetahuan dari beberapa petugas kesehatan puskesmas, dilihat dari observasi langsung ke ruangan, tidak semua ruangan diberikan panduan atau SOP mengenai pengelolaan sampah medis. Selain itu, petugas kesehatan yang bertugas untuk melakukan pengisian checklist setelah mengumpulkan sampah medis dari ruangan hanya 1 orang, oleh karena itu kemungkinan tidak semua petugas kesehatan mengetahui betul upaya pengelolaan yang tepat.

Pengetahuan

tentang

pengelolaan sampah medis yang baik belum tentu diikuti dengan tindakan pengelolaan sampah medis yang baik pula. Oleh karena itu, pemberian pengetahuan tambahan dengan sasaran tepat tentang pengelolaan sampah medis harus terlaksana dengan tujuan kedepannya yaitu petugas kesehatan dapat melakukan tindakan yang sesuai dengan peraturan yang berlaku di tempat kerjanya dikarenakan beberapa jenis sampah memerlukan penanganan khusus dan tindakan yang sesuai dalam upaya pengelolannya dapat meminimalisir dapak negatif yang dapat ditimbulkan ${ }^{8}$.

b. Hubungan sikap dengan tindakan dalam upaya pengelolaan sampah medis

Tabel 2.

Tabulasi Silang Sikap Terhadap Tindakan Petugas Kesehatan Dalam Upaya Pengelolan Sampah Medis Di Puskemas Dawan II Tahun 2021

\begin{tabular}{|c|c|c|c|c|c|c|c|}
\hline \multirow{3}{*}{ Sikap } & \multicolumn{4}{|c|}{ Tindakan } & \multirow{2}{*}{\multicolumn{2}{|c|}{ Total }} & \multirow{3}{*}{$\begin{array}{c}P- \\
\text { Value }\end{array}$} \\
\hline & \multicolumn{2}{|c|}{ Tidak Baik } & \multicolumn{2}{|c|}{ Baik } & & & \\
\hline & $\mathbf{N}$ & $\%$ & $\mathbf{N}$ & $\%$ & $\mathbf{n}$ & $\%$ & \\
\hline Negatif & 4 & 6,3 & 1 & 1,6 & 5 & 7,9 & \\
\hline Positif & 5 & 7,9 & 53 & 84,1 & 58 & 92,1 & 0,000 \\
\hline \multirow[t]{2}{*}{ Total } & 9 & 14,3 & 54 & 85,7 & 63 & 100 & \\
\hline & \multicolumn{6}{|c|}{$\mathrm{OR}=42,4 ; \mathrm{CI} 95 \%=3,942-456,032$} & \\
\hline
\end{tabular}




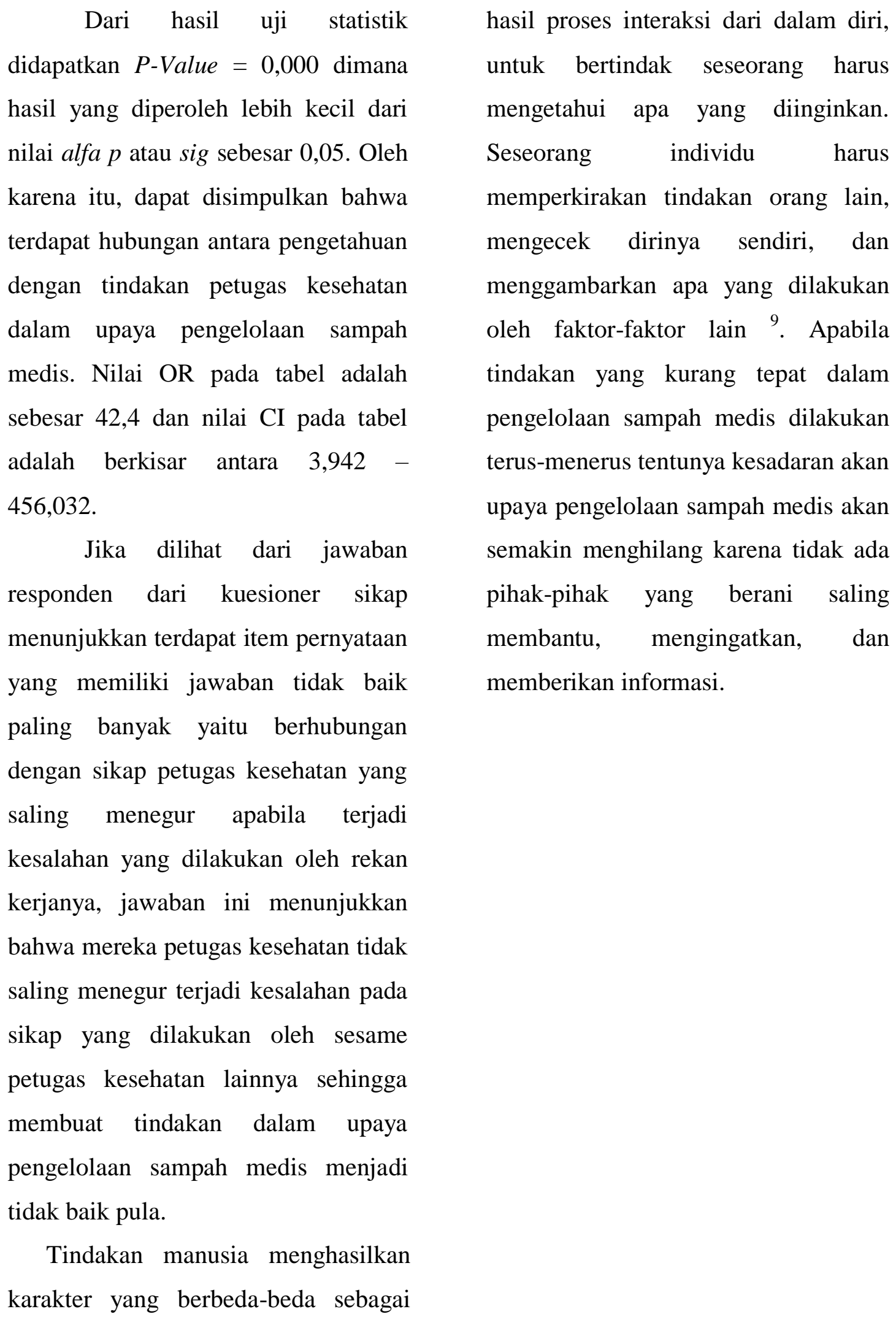




\section{SIMPULAN DAN SARAN}

Berdasarkan hasil penelitian yang dilakukan pada 63 responden tentang Hubungan Pengetahuan dan Sikap Dengan Tindakan Petugas Kesehatan Dalam Upaya Pengelolaan Sampah Medis di Puskesmas Dawan II Tahun 2021, maka dapat ditarik kesimpulan sebagai berikut :

1. Dalam upaya pengelolaan sampah medis puskesmas, sebanyak $85,7 \%$ petugas kesehatan (responden) memiliki pengetahuan baik. Petugas kesehatan yang memiliki sikap positif sebanyak $92,1 \%$. Tindakan petugas kesehatan dengan kategori baik sebesar $85,7 \%$.

2. Terdapat hubungan antara pengetahuan dengan tindakan petugas kesehatan tentang pengelolaan sampah medis rumah sakit, hal ini ditunjukkan oleh nilai $P$-Value $=0,000$ dimana hasil ini lebih kecil dari nilai alfa $p=0,05$.

3. Terdapat hubungan antara sikap dengan tindakan petugas kesehatan tentang pengelolaan sampah medis rumah sakit, hal ini ditunjukkan oleh nilai $P$-Value $=$ 0,000 dimana hasil ini lebih kecil dari nilai alfa $p=0,05$.

Berdasarkan kesimpulan diatas, adapun saran yang dapat diberikan sebagai berikut :

1. Bagi Kepala Puskesmas Dawan II, diharapkan memberikan mengarahkan dan memberikan pelatihan yang baik kepada petugas kesehatan tentang pengelolaan sampah medis, bisa dilakukan dengan cara mengajukan pelaksanaan diklat ke pihak pemerintah daerah maupun

Dinas Kesehatan Kabupaten Klungkung. Selain itu, setiap ruangan pelayanan kesehatan puskesmas harus dilengapi dengan SOP pengelolaan sampah medis dari sumbernya, serta adanya pengawasan terhadap perilaku pengelolaan sampah medis.

2. Bagi petugas kesehatan Puskesmas Dawan II agar lebih meningkatkan pengetahuan dibidang pengelolaan sampah medis, pihak yang lebih mengerti dalam bidang kesehatan 


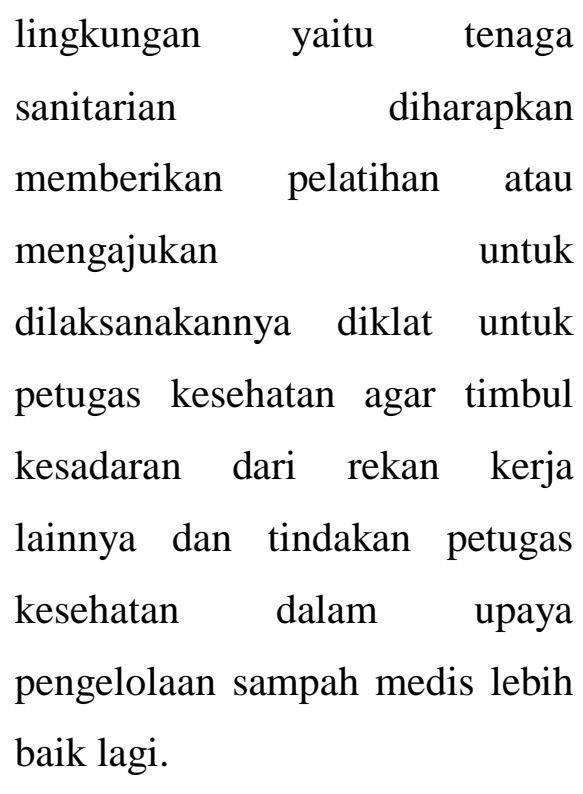

3. Bagi peneliti selanjutnya agar dapat menggunakan penelitian ini sebagai salah satu acuan dalam melakukan penelitian lanjutan, dengan tentunya memeriksa kembali dan menambahkan variabel-variabel pendukung yang lebih banyak seperti jenis pekerjaan, perbedaan pengambilan data sesuai shift petugas kesehatan, jenis teknik sampling yang berbeda dengan pengelompokkan khusus sehingga penelitian sejenis dapat lebih berkembang.

\section{DAFTAR PUSTAKA}

1. Depkes, R. Kepmenkes RI

No.1428/Menkes/SK/XII/2006

Tentang Pedoman

Penyelenggaraan Kesehatan

Lingkungan Puskesmas.

Jakarta: Departemen Kesehatan

RI. (2006).

2. Rahmin, A. R. Kumpulan

Artikel Kesehatan Masyarakat

di Daerah Terpencil,

Perbatasan, dan Kepulauan.

Yogyakarta : Leutikaprio.

(2019).

3. Astuti, A. Kajian Pengelolaan

Limbah di Rumah Sakit Umum

Provinsi Nusa Tenggara Barat

(NTB).Universitas Udayana.

2014. (2014).

4. Ariella, L. Faktor-Faktor Yang

Berhubungan Dengan Perilaku

Perawat Dalam Penanganan

Sampah Medis Padat di

Puskesmas Bukittinggi Tahun

2014: FKM Unand. 2014.

(2014).

5. Sugiyono. Metode Penelitian

Pendidikan Pendekatan

Kuantitatif, Kualitatif, dan

$R \& D$. (Alfabeta.). 
6. Moleong, L. J. Metodologi

Penelitian Kualitatif. (Remaja

Rosdakarya, 2007).

7. Notoatmodjo. Metodologi

Penelitian Kesehatan. (PT.

Rineka Cipta, 2014).

8. Fahriyah, L. Pengetahuan dan

Sikap dengan Perilaku Perawat

dalam Pemilahan dan
Pewadahan Limbah Medis

Padat. Universitas Lambung

Mangkurat. (2015).

9. Tarigan, I. Determinan

Tindakan Perawat dalam

Membuang Limbah Medis

Padat Di Rumah Sakit Umum

dr. Pirngadi Kota Medan Tahun

2008. USU. 2008. (2008). 